\title{
Project Management with Special Reference to IT Management and Allied Areas: An Overview
}

\author{
P.K. Paul ${ }^{*}$, A. Bhuimali², Kalishankar Tiwary ${ }^{3}$, P.S. Aithal ${ }^{4}$ and R. Rajesh ${ }^{5}$ \\ ${ }^{I}$ Department of CIS, Raiganj University (RGU), West Bengal, India \\ ${ }^{2}$ Vice Chancellor, Raiganj University, West Bengal, India \\ ${ }^{2} H o D$, Mathematics \& Director-IQAC, Raiganj University, West Bengal, India \\ ${ }^{4}$ Vice Chancellor, Srinivas University, Karnataka, India \\ ${ }^{5}$ Principal, Rohini College of Engineering and Technology, Tamil Nadu, India \\ *Corresponding author: pkpaul.infotech@gmail.com
}

\begin{abstract}
IT project management depends on different kind of attributes such as planning, organizing, and different kind of affairs in information technology (IT) goals. IT project management is also responsible for the various kind of software development, hardware and network,install and upgrades, cloud computing and virtualization establishment, analytics and data management projects etc. IT Project Management now a day's is not only an area or working affair for better IT affairs but also s field of study. Internationally many universities have started the program on IT Management with different level viz. Bachelor, Masters, Doctoral. This paper is conceptual in nature and mainly deals with the basic concept of IT Management, Function and features of IT Management. The paper also explores about the emergence of IT Management related areas and including the basic role of IT Manager in simple and general context.
\end{abstract}

Keywords: Information Technology, IT Systems, Information, Systems Science, Management, Organizational Development, Project Management

Information Technology Management is one of the important and valuable names in today's age and it is required and practiced in different areas. Apart from IT Companies and Software Development units, IT Management is needed in different areas and sectors viz. healthcare, tourism, government, education and e-learning etc. ${ }^{[1],[7],[9]}$. The IT project management deals with several areas which include the life cycle and are universal to all projects. The specific phases are unique to each project and there are many steps in IT Project Management and among these few important are: 
Initiation: This includes the initiation of the any IT project

Planning: This includes the planning in IT Project execution etc.

$\square$ Execution: This includes the execution of the IT related works and project related affairs.

$\square$ Monitoring and controlling: This includes the IT project monitoring and controlling and other works viz. time, cost, scope, quality, risk, and other factors of the project. An IT Manager should know these things carefully and also should perform accordingly.

$\square$ Closing: The closing is another important step that may be possible to bring out and here IT Manager has to do many things separately.

Worldwide, every organization and institution are doing well in IT Management and in this regard, these steps are important and are valuable. This paper talks about other allied and related areas ${ }^{[2],[3],[12]}$.

\section{Objective}

The main objective of the paper includes (but not limited) the following:

$\square$ To learn about the basics of Management and also Principles of Management in a brief manner.

$\square$ To know about the basics of Project Management and its features and function in a brief and concise manner.

$\square$ To learn about the basics of IT Project Management and its role with a core value.

$\square$ To learn about the related areas of IT Project Management like IT Infrastructure, Converged Infrastructure, IT Service Management etc.

$\square$ To learn about the role of IT Manager and their role in the development of IT Systems and Information Organization Development.

$\square$ To dig out the future research potentialities and trends in IT Project Management in the technomanagerial context.

\section{Project Management: The Meaning}

Project management is an important part of Management. Project management deals with various kind of project, plans, executing, forecasting and importantly controlling any kind of work (may be tangible or intangible). Means project management is about the application of following management principles (POSDCORB):

$\square$ Planning

$\square$ Organizing

$\square$ Staffing

$\square$ Directing

$\square$ Coordinating

$\square$ Reporting

$\square$ Budgeting 
In project management other areas of management such as strategic management, SWOT analysis, TQM (Total Quality Management) are also important for an issue in project management. The basic IT Management process is depicted in Fig. 1 herewith.

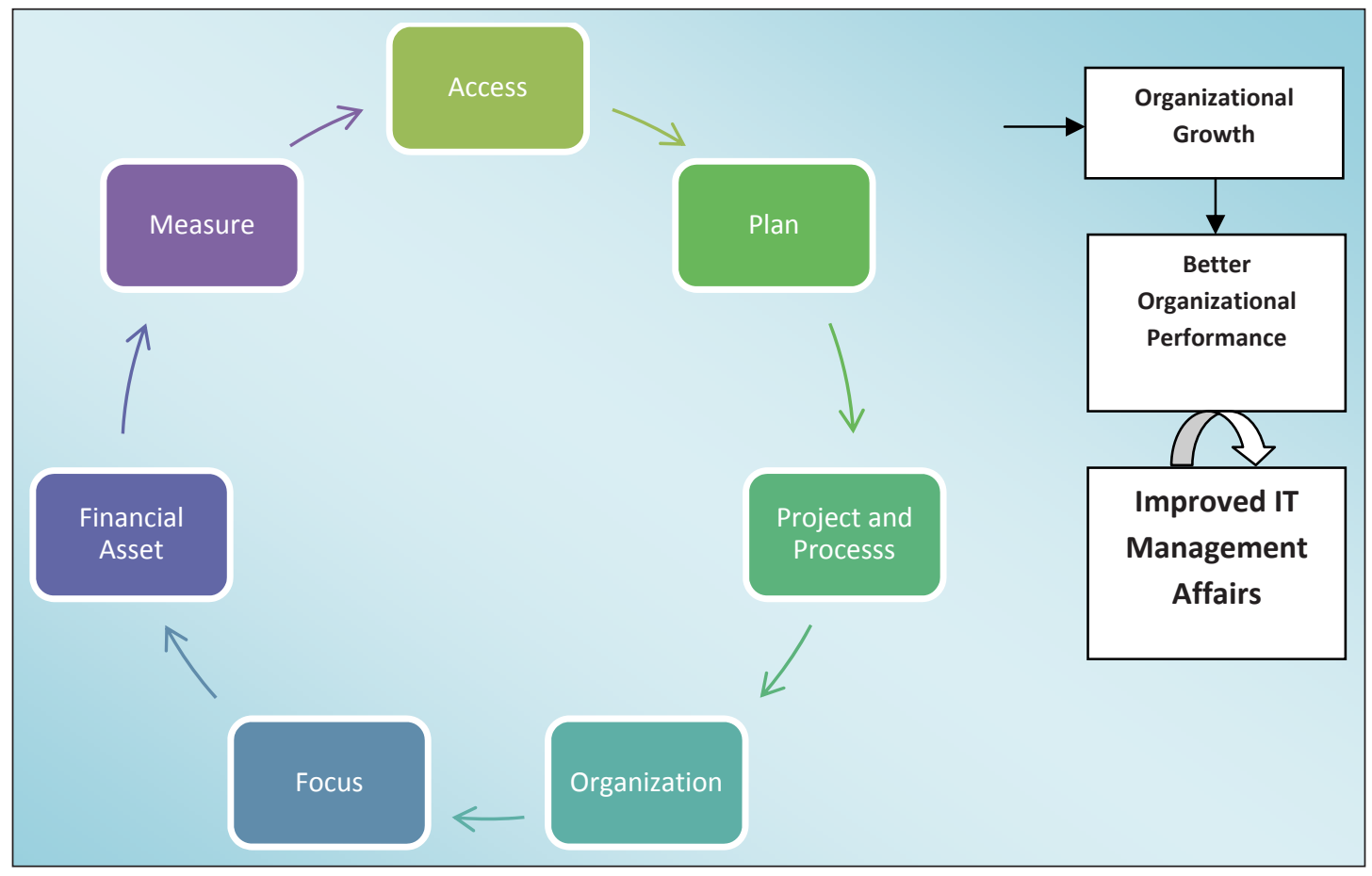

Fig. 1: IT Management Process

\section{IT Project Management}

IT Project management is an application of project management technique in Information project management field ${ }^{[4],[5],[10]}$. It includes planning, forecasting, executing, implementing IT related affairs. Such as:

$\square$ Project related tool.

$\square$ IT infrastructure and implementation.

$\square$ Implementing a software project.

$\square$ Design development and implementation of IT project, in terms of network.

$\square$ Managing and executing a large number and large scale of database.

IT project management is a real time IT application in the organizations and industries. The IT Project Management is also valuable in different kind of organizations and institutions those who are employing IT for different purposes.

The core of IT management include the use of technology and in this regard business strategies and technologies are must and important in different context. 
IT Management is a different area than that of MIS i.e. management information systems. MIS is actually a management method and is responsible for the automation and also for the support of human decision support system creation whereas; IT Management is nothing but the IT related affairs in the organizations ${ }^{[5],[8],[13]}$.

MIS is business focused and whereas IT management is powered by the technology. IT Management depends on both technology as well as business strategies. It is worthy to note that the both internal and external environments, technology components etc play an important role for an organizational IT Management. It is important to note that both, business as well modern technology management required for better and healthy IT Management in a different context.

There are many technologies involved with IT Management and allied areas and among these few important are include (but not limited to):

$\square$ Converged Infrastructure

$\square$ Converge servers, storage, networking,

$\square$ Security, management, and facilities.

The efficiencies of IT Management include the integrated and automated management systems that provide more faster having manageability and maintenance capability in IT Services. It also enables IT systems in better and healthy IT resources which include the servers, storage and networking etc based on business demand. In generally IT Management depends on different kind of process and steps and ultimately in IT Management it helps different IT spaces and sectors, the details are depicted in Fig. 2 in concentration with 4Ps of Management Sciences.

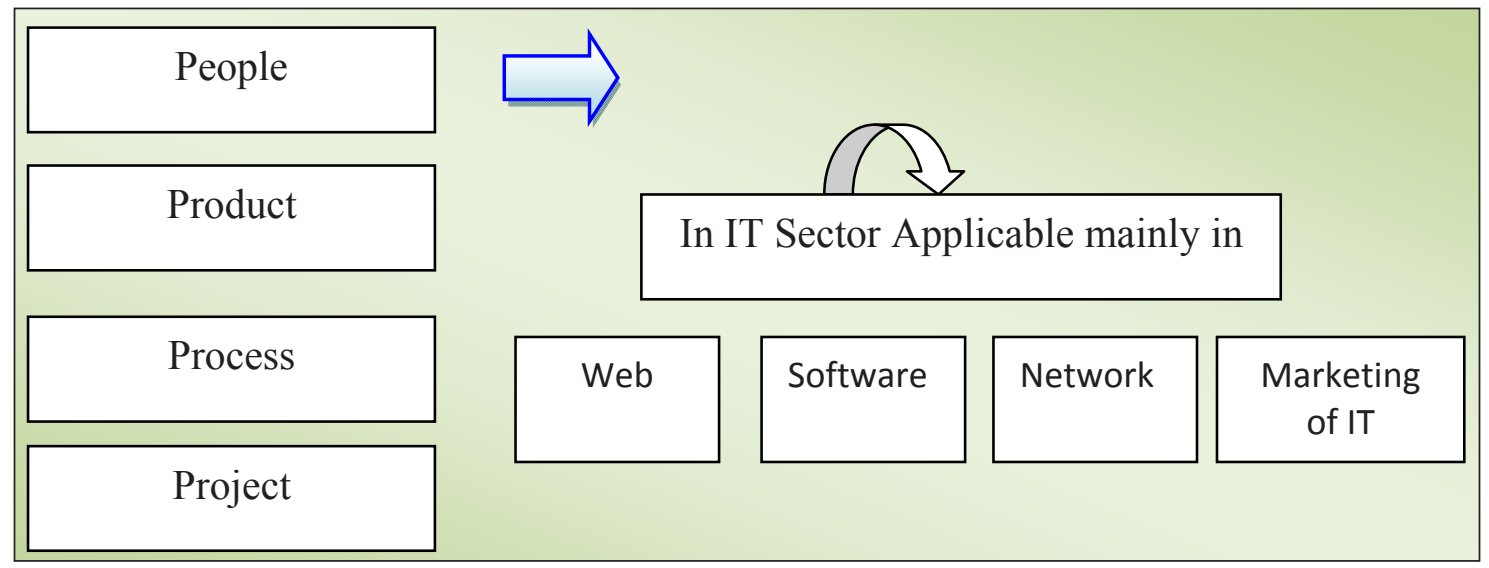

Fig. 2: 4Ps and Ultimate benefits of the IT Management

\section{Related Areas of IT Management}

The Information Technology Management areas consist with many domains and fields and among these few important are IT Infrastructure, Converged Infrastructure, Hyper Converged Infrastructure, Financial Management of IT Services, IT Service Management, Configuration Management etc. ${ }^{[6],[14],[16]}$. 


\section{IT Infrastructure}

Information Technology Infrastructure is actually a set of information technology components and these are treated as a foundation of an IT service. Within IT Infrastructure physical components are also treated as most valuable viz. computer and networking hardware and also various software and network components.

IT management and IT service management is purely depends on IT infrastructure, and here best set of practices are required in respect to IT infrastructure.

Enterprise IT infrastructure needs several facets viz. operation of an enterprise IT environment and it can be deployed within owned facilities, or by using different kind of facilities including use of cloud technologies.

\section{Converged Infrastructure}

Converged infrastructure is a combination of multiple information technology elements and components in a single as well as optimized computing package. Following are few components of the Converged Infrastructure:

$\square$ Servers and allied devices.

$\square$ Data storage devices and systems.

$\square$ Networking equipment and tools.

$\square$ Software for IT infrastructure management and allied services.

IT organizations, as well as institutions in-generally, use a different kind of converged infrastructure to consolidate systems and for increasing resource-utilization rates. Converged infrastructures help in gaining the core aim and objectives by the use of computers, storage and networking and here multiple applications may be managed but policy-driven processes are preferred. It is a fact that IT industry analysts use the following concepts and term in respect of Converge Infrastructure viz.

$\square$ Converged system

$\square$ Unified computing

Fabric-based computing

$\checkmark$ Dynamic infrastructure etc.

\section{Hyper-Converged Infrastructure}

Hyper-converged infrastructure is a Software Defined Network which is responsible for the virtualization of different elements of conventional IT infrastructure. HCI is also responsible for the virtualization of the computing, a virtualized SAN i.e. actually software-defined storage and also about the virtualized networking. It is important to note that HCI typically runs on COTS servers ${ }^{[7],[12],[15]}$.

There are many differences between converged infrastructure and hyper-converged infrastructure. And it is important to note that in HCI both the SAN and the storage abstractions are used but that of physically. 


\section{Financial Management for IT Services}

It is a Service Science and Service Strategy element; it is mainly responsible for the giving accurate and cost-effective systems in providing IT Services. Importantly it is for the plan, control as well as for the recovering costs for the purpose of service-level agreement i.e. SLA.

\section{IT Service Management}

IT Service Management is actually governed by the policies, and also organized systems for IT; it is also structure processes etc. It is required for the organization for different reason viz. design, plan, deliver, operate as well as control of information technology services; hence here the implementation of IT services is important and valuable which are valuable to meet customers and client need, thus here a combination of the following are must:

$\square$ People

$\square$ Process and

$\square$ Information technology etc.

Network Management, IT Systems Management, IT Service Management etc are closely associated and related areas and fields. Here, customers need and importance are must and valuable.

\section{Configuration Management}

Configuration Management in short called as $C M$ and it is a kind of systems engineering process for managing and maintaining consistency in IT product's performance. Moreover, it is also required for the purpose of functional and physical attributes for the purpose of design and operational information; ultimately it is worthy to note that CM is required in advance IT Management ${ }^{[3],[11],[15]}$.

\section{IT Management, IT Managers and Roles}

IT managers in this days should know about the project management as well, they are also a kind of IT Project Manager. IT manager is responsible for the ongoing program of IT services and also future affairs.

The professionals in this field mainly generated from the IT Management Education Degree and they have effectively done various things viz. planning, design, selection, implementation, including converging of different information and communications technology tools and products. Actually, technical knowledge, as well as management knowledge both are essential in this regard and here few things are important viz. integrating people, information and business processes to achieve strategic goals of an organization and business.

It is a fact that here are also difficulties IT management and professionals need to do on that. The increasing amount of data lead the advancement in IT Managers work and, in this respect, additionally, Data security, quality, and integrity are also valuable. Understanding the affairs on the Data Governance are also important and valuable. 


\section{CONCLUSION}

Information Technology Management has many advantages, but it also has various disadvantages such as with sufficient IT usages, emotional contacts among the staffs, and hence client may decrease in time. We know that information infrastructure is a technical structure and a concept and hence it also includes manual as well as computational Information Management. There is a misconception that IT Management is required only in IT Companies and organizations but today IT Management principles and systems are required in other organizations and systems that use IT tools and products. IT Management has many strong and advance areas but still, it has many disadvantages viz. Information Security, Information Privacy, Information Overloading etc. Every organization and institution need to play a sophisticated way to practice IT Management as per the need.

\section{REFERENCES}

1. Ayas, K. 1996. Professional project management: a shift towards learning and a knowledge creating structure. International Journal of Project Management, 14(3): 131-136.

2. Bernroider, E.W. and Ivanov, M. 2011. IT project management control and the Control Objectives for IT and related Technology (CobiT) framework. International Journal of Project Management, 29(3): 325-336.

3. De Bakker, K., Boonstra, A. and Wortmann, H. 2010. Does risk management contribute to IT project success? A meta-analysis of empirical evidence. International Journal of Project Management, 28(5): 493-503.

4. Keil, M. 1995. Pulling the plug: Software project management and the problem of project escalation. MIS quarterly, 421-447.

5. Lee-Kelley, L. and Kin Leong, L. 2003. Turner's five-functions of project-based management and situational leadership in IT services projects. International Journal of Project Management, 21(8): 583-591.

6. Legris, P. and Collerette, P. 2006. A roadmap for IT project implementation: Integrating stakeholders and change management issues. Project Management Journal, 37(5): 64-75.

7. Munns, A.K. and Bjeirmi, B.F. 1996. The role of project management in achieving project success. International Journal of Project Management, 14(2): 81-87.

8. Napier, N.P., Keil, M. and Tan, F.B. 2009. IT project managers' construction of successful project management practice: a repertory grid investigation. Information Systems Journal, 19(3): 255-282.

9. Nelson, R.R. 2007. IT project management: Infamous failures, classic mistakes, and best practices. MIS Quarterly Executive, 6(2).

10. Rodrigues, A. and Bowers, J. 1996. The role of system dynamics in project management. International Journal of Project Management, 14(4): 213-220.

11. Sauer, C. and Reich, B.H. 2009. Rethinking IT project management: Evidence of a new mindset and its implications. International Journal of Project Management, 27(2): 182-193. 
12. Tadeu de Oliveira Lacerda, R., Ensslin, L. and Rolim Ensslin, S. 2011. A performance measurement view of IT project management. International Journal of Productivity and Performance Management, 60(2): 132-151.

13. Tesch, D., Kloppenborg, T.J. and Frolick, M.N. 2007. IT project risk factors: the project management professionals perspective. Journal of Computer Information Systems, 47(4): 61-69.

14. Thomas, J. and Mengel, T. 2008. Preparing project managers to deal with complexity-Advanced project management education. International Journal of Project Management, 26(3): 304-315.

15. Wateridge, J. 1995. IT projects: a basis for success. International Journal of Project Management, 13(3): 169-172.

16. Wateridge, J. 1997. Training for IS/IT project managers: a way forward. International Journal of Project Management, 15(5): 283-288. 